\title{
Optimal simple and implementable monetary and fiscal rules ${ }^{\text {ts }}$
}

\author{
Stephanie Schmitt-Grohé*, Martín Uribe
}

CEPR and NBER, Duke University, USA

Received 22 June 2006; received in revised form 28 June 2006; accepted 17 July 2006

Available online 16 October 2006

\begin{abstract}
Welfare-maximizing monetary- and fiscal-policy rules are studied in a model with sticky prices, money, and distortionary taxation. The Ramsey-optimal policy is used as a point of comparison. The main findings are: the size of the inflation coefficient in the interest-rate rule plays a minor role for welfare. It matters only insofar as it affects the determinacy of equilibrium. Optimal monetary policy features a muted response to output. Interest-rate rules that feature a positive response to output can lead to significant welfare losses. The welfare gains from interest-rate smoothing are negligible. Optimal fiscal policy is passive. The optimal monetary and fiscal rule combination attains virtually the same level of welfare as the Ramsey-optimal policy.
\end{abstract}

(C) 2006 Elsevier B.V. All rights reserved.

JEL classification: E52; E61; E63

Keywords: Policy evaluation; Optimal policy; Nominal rigidities

\footnotetext{
This paper is a substantial revised version of an earlier version with the same title that circulated as NBER working paper 10253. We thank for comments an anonymous referee, Tommaso Monacelli, Robert Kollmann, Lars Svensson, and seminar participants at University Bocconi, the Bank of Italy, the CEPR-INSEAD Workshop on Monetary Policy Effectiveness, and Banco de la República (Bogotá, Colombia).

*Corresponding author. Tel.: + 19196601889.

E-mail addresses: grohe@duke.edu (S. Schmitt-Grohé), uribe@duke.edu (M. Uribe).
} 


\section{Introduction}

Recently, there has been an outburst of papers studying optimal monetary policy in economies with nominal rigidities. ${ }^{1}$ Most of these studies are conducted in the context of highly stylized theoretical and policy environments. For instance, in much of this body of work it is assumed that the government has access to a subsidy to factor inputs, financed with lump-sum taxes, aimed at dismantling the inefficiency introduced by imperfect competition in product and factor markets. This assumption is clearly empirically unrealistic. But more importantly it undermines a potentially significant role for monetary policy, namely, stabilization of costly aggregate fluctuations around a distorted steadystate equilibrium.

A second notable simplification is the absence of capital accumulation. All the way from the work of Keynes (1936) and Hicks (1939) to that of Kydland and Prescott (1982) macroeconomic theories have emphasized investment dynamics as an important channel for the transmission of aggregate disturbances. It is therefore natural to expect that investment spending should play a role in shaping optimal monetary policy. Indeed it has been shown that for a given monetary regime the determinacy properties of a standard neo-Keynesian model can change dramatically when the assumption of capital accumulation is added to the model (Dupor, 2001; Carlstrom and Fuerst, 2005).

A third important dimension along which the existing studies abstract from reality is the assumed fiscal regime. It is standard practice in this literature to completely ignore fiscal policy. Implicitly, these models assume that the fiscal budget is balanced at all times by means of lump-sum taxation. In other words, fiscal policy is always assumed to be nondistorting and passive in the sense of Leeper (1991). However, empirical studies, such as Favero and Monacelli (2003), show that characterizing postwar U.S. fiscal policy as passive at all times is at odds with the facts. In addition, it is well known theoretically that, given monetary policy, the determinacy properties of the rational expectations equilibrium crucially depend on the nature of fiscal policy (e.g., Leeper, 1991). It follows that the design of optimal monetary policy should depend upon the underlying fiscal regime in a nontrivial fashion.

Fourth, model-based analyses of optimal monetary policy is typically restricted to economies in which long-run inflation is nil or there is some form of widespread indexation. As a result, nominal rigidities have no real consequences for economic activity and thus welfare in the long run. It follows that the assumptions of zero long-run inflation or indexation should not be expected to be inconsequential for the form that optimal monetary policy takes. Because from an empirical point of view, neither of these two assumptions is particularly compelling for economies like the United States, it is of interest to investigate the characteristics of optimal policy in their absence.

Last but not least, more often than not studies of optimal policy in models with nominal rigidities are conducted in cashless environments. ${ }^{2}$ This assumption introduces an inflation-stabilization bias into optimal monetary policy. For the presence of a demand for money creates a motive to stabilize the nominal interest rate rather than inflation.

Taken together the simplifying assumptions discussed above imply that business cycles are centered around an efficient nondistorted equilibrium. The main reason why these

\footnotetext{
${ }^{1}$ See Rotemberg and Woodford (1997, 1999), Clarida et al. (1999), Galí and Monacelli (2005), and SchmittGrohé and Uribe $(2001,2004 b)$ among many others.

${ }^{2}$ Exceptions are Khan et al. (2003) and Schmitt-Grohé and Uribe (2004b).
} 
rather unrealistic features have been so widely adopted is not that they are the most empirically obvious ones to make nor that researchers believe that they are inconsequential for the nature of optimal monetary policy. Rather, the motivation is purely technical. Namely, the stylized models considered in the literature make it possible for a first-order approximation to the equilibrium conditions to be sufficient to accurately approximate welfare up to second order. Any plausible departure from the set of simplifying assumptions mentioned above, with the exception of the assumption of no investment dynamics, would require approximating the equilibrium conditions to second order.

Recent advances in computational economics have delivered algorithms that make it feasible and simple to compute higher-order approximations to the equilibrium conditions of a general class of large stochastic dynamic general equilibrium models. ${ }^{3}$ In this paper, we employ these new tools to analyze a model that relaxes all of the questionable assumptions mentioned above. The central focus of this paper is to investigate whether the policy conclusions arrived at by the existing literature regarding the optimal conduct of monetary policy are robust with respect to more realistic specifications of the economic environment. That is, we study optimal policy in a world where there are no subsidies to undo the distortions created by imperfect competition, where there is capital accumulation, where the government may follow active fiscal policy and may not have access to lumpsum taxation, where nominal rigidities induce inefficiencies even in the long run, and where there is a nonnegligible demand for money.

Specifically, this paper characterizes monetary- and fiscal-policy rules that are optimal within a family of implementable, simple rules in a calibrated model of the business cycle. In the model economy, business cycles are driven by stochastic variations in the level of total factor productivity and government consumption. The implementability condition requires policies to deliver uniqueness of the rational expectations equilibrium. Simplicity requires restricting attention to rules whereby policy variables are set as a function of a small number of easily observable macroeconomic indicators. Specifically, we study interest-rate feedback rules that respond to measures of inflation, output, and lagged values of the nominal interest rate. We analyze fiscal-policy rules whereby the tax revenue is set as an increasing function of the level of public liabilities. The optimal simple and implementable rule is the simple and implementable rule that maximizes welfare of the individual agent. As a point of comparison for policy evaluation, we compute the real allocation associated with the Ramsey-optimal policy.

Our findings suggest that the precise degree to which the central bank responds to inflation in setting the nominal interest rate (i.e., the size of the inflation coefficient in the interest-rate rule) plays a minor role for welfare provided that the monetary/fiscal regime renders the equilibrium unique. For instance, in all of the many environments we consider, deviating from the optimal policy rule by setting the inflation coefficient anywhere above unity yields virtually the same level of welfare as the optimal rule. Thus, the fact that optimal policy features an active monetary stance serves mainly the purpose of ensuring the uniqueness of the rational expectations equilibrium. Second, optimal monetary policy features a muted response to output. More importantly, not responding to output is critical from a welfare point of view. In effect, our results show that interest-rate rules that feature a positive response of the nominal interest rate to output can lead to significant welfare losses. Third, the welfare gains from interest-rate smoothing are negligible. Fourth,

${ }^{3}$ See for instance, Schmitt-Grohé and Uribe (2004a) and Sims (2000). 
the optimal fiscal policy is passive. Fifth, an interest-rate feedback rule that responds only to lagged information performs as well as one that responds to contemporaneous information. Finally, the optimal simple and implementable policy rule attains virtually the same level of welfare as the Ramsey-optimal policy.

Kollmann (2003) also considers welfare-maximizing fiscal and monetary rules in a sticky price model with capital accumulation. He also finds that optimal monetary policy features a strong anti-inflationary stance. However, the focus of his paper differs from ours in a number of dimensions. First, Kollmann does not consider the size of the welfare losses that are associated with nonoptimal rules, which is at center stage in our work. Second, in his paper the interest-rate feedback rule is not allowed to depend on a measure of aggregate activity and as a consequence the paper does not identify the importance of not responding to output. Third, Kollmann limits attention to a cashless economy with zero long-run inflation. Finally, in Kollmann's paper policy evaluation does not take the Ramseyoptimal policy as the point of comparison.

The remainder of the paper is organized in six sections. Section 2 presents the model. Section 3 presents the calibration of the model and discusses computational issues. Section 4 computes optimal policy in a cashless economy. Section 5 analyzes optimal policy in a monetary economy. Section 6 introduces fiscal instruments as part of the optimal policy design problem. Section 7 concludes.

\section{The model}

The starting point for our investigation into the welfare consequences of alternative policy rules is an economic environment featuring a blend of neo-classical and neoKeynesian elements. Specifically, the skeleton of the economy is a standard real-businesscycle model with capital accumulation and endogenous labor supply driven by technology and government spending shocks. Five sources of inefficiency separate our model from the standard RBC framework: (a) nominal rigidities in the form of sluggish price adjustment. (b) A demand for money by firms motivated by a working-capital constraint on labor costs. (c) A demand for money by household originated in a cash-in-advance constraint. (d) Monopolistic competition in product markets. And (e) time-varying distortionary taxation. These five elements of the model provide a rationale for the conduct of monetary and fiscal stabilization policy.

We keep the presentation of the model concise and refer the reader to the expanded version of this paper (Schmitt-Grohé and Uribe, 2006b) for a more elaborate derivation.

\subsection{Households}

The economy is populated by a continuum of identical infinitely lived households. Each household has preferences defined over consumption, $c_{t}$, and labor effort, $h_{t}$. Preferences are described by the utility function

$$
\mathrm{E}_{0} \sum_{t=0}^{\infty} \beta^{t} \mathrm{U}\left(c_{t}, h_{t}\right),
$$

where $\mathrm{E}_{t}$ denotes the mathematical expectations operator conditional on information available at time $t, \beta \in(0,1)$ represents a subjective discount factor, and $\mathrm{U}$ is a period 
utility index assumed to be strictly increasing in its first argument, strictly decreasing in its second argument, and strictly concave. The consumption good is assumed to be a composite good produced with a continuum of differentiated goods, $c_{i t}, i \in[0,1]$, via the aggregator function

$$
c_{t}=\left[\int_{0}^{1} c_{i t}^{1-1 / \eta} \mathrm{d} i\right]^{1 /(1-1 / \eta)},
$$

where the parameter $\eta>1$ denotes the intratemporal elasticity of substitution across different varieties of consumption goods. For any given level of consumption of the composite good, purchases of each variety $i$ in period $t$ must solve the dual problem of minimizing total expenditure, $\int_{0}^{1} P_{i t} c_{i t} \mathrm{~d} i$, subject to the aggregation constraint (1), where $P_{i t}$ denotes the nominal price of a good of variety $i$ at time $t$. The optimal level of $c_{i t}$ is then given by

$$
c_{i t}=\left(\frac{P_{i t}}{P_{t}}\right)^{-\eta} c_{t},
$$

where $P_{t}$ is a nominal price index given by

$$
P_{t} \equiv\left[\int_{0}^{1} P_{i t}^{1-\eta} \mathrm{d} i\right]^{1 /(1-\eta)} .
$$

This price index has the property that the minimum cost of a bundle of intermediate goods yielding $c_{t}$ units of the composite good is given by $P_{t} c_{t}$.

Households are assumed to have access to a complete set of nominal contingent claims. Expenditures on consumption are subject to a cash-in-advance constraint of the form

$$
m_{t}^{\mathrm{h}} \geqslant v^{\mathrm{h}} c_{t}
$$

where $m_{t}^{\mathrm{h}}$ denotes real money holdings by the household in period $t$ and $v^{\mathrm{h}} \geqslant 0$ is a parameter. The household's period-by-period budget constraint is given by

$$
\begin{aligned}
\mathrm{E}_{t} d_{t, t+1} \frac{x_{t+1}}{P_{t}}+m_{t}^{\mathrm{h}}+c_{t}+i_{t}+\tau_{t}^{\mathrm{L}}= & \frac{x_{t}}{P_{t}}+\frac{P_{t-1}}{P_{t}} m_{t-1}^{\mathrm{h}}+\left(1-\tau_{t}^{\mathrm{D}}\right) \\
& \times\left[w_{t} h_{t}+u_{t} k_{t}\right]+\delta \tilde{q}_{t} \tau_{t}^{\mathrm{D}} k_{t}+\tilde{\phi}_{t},
\end{aligned}
$$

where $d_{t, s}$ is a stochastic discount factor, defined so that $\mathrm{E}_{t} d_{t, s} x_{s}$ is the nominal value in period $t$ of a random nominal payment $x_{s}$ in period $s \geqslant t$. The variable $k_{t}$ denotes capital, $i_{t}$ denotes gross investment, $\tilde{\phi}_{t}$ denotes profits received from the ownership of firms net of income taxes, $\tau_{t}^{\mathrm{D}}$ denotes the income tax rate, and $\tau_{t}^{\mathrm{L}}$ denotes lump-sum taxes. The variable $\tilde{q}_{t}$ denotes the market price of one unit of installed capital. The term $\delta \tau_{t}^{\mathrm{D}} \tilde{q}_{t} k_{t}$ represents a depreciation allowance for tax purposes.

The capital stock is assumed to depreciate at the constant rate $\delta$. The evolution of capital is given by

$$
k_{t+1}=(1-\delta) k_{t}+i_{t} .
$$

The investment good is assumed to be a composite good made with the aggregator function (1). Thus, the demand for each intermediate good $i \in[0,1]$ for investment purposes, denoted by $i_{i t}$, is given by $i_{i t}=\left(P_{i t} / P_{t}\right)^{-\eta} i_{t}$. Households are also assumed to be subject to a borrowing limit that prevents them from engaging in Ponzi schemes. 
In this environment, the income tax rate as well as the opportunity cost of holding money (the interest rate) distort both the leisure-labor choice and the decision to accumulate capital over time.

\subsection{The government}

The consolidated government prints money, $M_{t}$, issues one-period nominal risk-free bonds, $B_{t}$, collects taxes in the amount of $P_{t} \tau_{t}$, and faces an exogenous expenditure stream, $g_{t}$. Its period-by-period budget constraint is given by

$$
M_{t}+B_{t}=R_{t-1} B_{t-1}+M_{t-1}+P_{t} g_{t}-P_{t} \tau_{t} .
$$

Here, $R_{t}$ denotes the gross one-period, risk-free, nominal interest rate in period $t$. The variable $g_{t}$ denotes per capita government spending on a composite good produced via aggregator (1). We assume, maybe unrealistically, that the government minimizes the cost of producing $g_{t}$. Thus, we have that the public demand for each type $i$ of intermediate goods, $g_{i t}$, is given by $g_{i t}=\left(P_{i t} / P_{t}\right)^{-\eta} g_{t}$. Let $\ell_{t-1} \equiv\left(M_{t-1}+R_{t-1} B_{t-1}\right) / P_{t-1}$ denote total real government liabilities outstanding at the end of period $t-1$ in units of period $t-1$ goods. Also, let $m_{t} \equiv M_{t} / P_{t}$ denote real money balances in circulation. Then the government budget constraint can be written as

$$
\ell_{t}=\frac{R_{t}}{\pi_{t}} \ell_{t-1}+R_{t}\left(g_{t}-\tau_{t}\right)-m_{t}\left(R_{t}-1\right),
$$

where $\pi_{t} \equiv P_{t} / P_{t-1}$ denotes the gross consumer price inflation.

We wish to consider various alternative fiscal-policy specifications that involve possibly both lump-sum and distortionary income taxation. Total tax revenues, $\tau_{t}$, consist of revenue from lump-sum taxation, $\tau_{t}^{\mathrm{L}}$, and revenue from income taxation, $\tau_{t}^{\mathrm{D}} y_{t}$, where $y_{t}$ denotes aggregate demand. ${ }^{4}$ That is,

$$
\tau_{t}=\tau_{t}^{\mathrm{L}}+\tau_{t}^{\mathrm{D}} y_{t}
$$

The fiscal regime is defined by the following rule:

$$
\tau_{t}-\tau^{*}=\gamma_{1}\left(\ell_{t-1}-\ell^{*}\right),
$$

where $\gamma_{1}$ is a parameter and $\tau^{*}$ and $\ell^{*}$ denote the deterministic Ramsey-steady-state values of $\tau_{t}$ and $\ell_{t}$, respectively. According to this rule, the fiscal authority sets tax revenues in period $t, \tau_{t}$, as a linear function of the real value of total government liabilities, $\ell_{t-1}$. Combining this fiscal rule with the government sequential budget constraint (3) yields

$$
\ell_{t}=\frac{R_{t}}{\pi_{t}}\left(1-\pi_{t} \gamma_{1}\right) \ell_{t-1}+R_{t}\left(\gamma_{1} \ell^{*}-\tau^{*}\right)+R_{t} g_{t}-m_{t}\left(R_{t}-1\right) .
$$

When $\gamma_{1}$ lies in the interval $\left(0,2 / \pi^{*}\right)$, we say, following the terminology of Leeper (1991), that fiscal policy is passive. Intuitively, in this case, in a stationary equilibrium near the deterministic steady state, deviations of real government liabilities from their nonstochastic steady-state level grow at a rate less than the real interest rate. As a result, the present

\footnotetext{
${ }^{4}$ In the economy with distortionary taxes only, we implicitly assume that profits are taxed in such a way that the tax base equals aggregate demand. In the absence of profit taxation, the tax base would equal $w_{t} h_{t}+\left(u_{t}-\delta q_{t}\right) k_{t}$. As shown in Schmitt-Grohé and Uribe (2004b, d), untaxed profits create an inflation bias in the Ramsey policy. This is because the Ramsey planner uses the inflation tax as an indirect tax on profits.
} 
discounted value of government liabilities is expected to converge to zero regardless of the stance of monetary policy. Alternatively, when $\gamma_{1}$ lies outside of the range $\left(0,2 / \pi^{*}\right)$, we say that fiscal policy is active. In this case, government liabilities grow at a rate greater than the real interest rate in absolute value in the neighborhood of the deterministic steady state. Consequently, the present discounted value of real government liabilities is not expected to vanish for all possible specifications of monetary policy. Under active fiscal policy, the price level plays an active role in bringing about fiscal solvency in equilibrium.

We focus on four alternative fiscal regimes. In two all taxes are lump sum $\left(\tau^{\mathrm{D}}=0\right)$, and in the other two all taxes are distortionary $\left(\tau^{\mathrm{L}}=0\right)$. We consider passive fiscal policy $\left(\gamma_{1} \in\left(0,2 / \pi^{*}\right)\right)$ and active fiscal policy $\left(\gamma_{1} \notin\left(0,2 / \pi^{*}\right)\right)$.

We assume that the monetary authority sets the short-term nominal interest rate according to a simple feedback rule belonging to the following class of Taylor (1993)-type rules

$$
\ln \left(R_{t} / R^{*}\right)=\alpha_{R} \ln \left(R_{t-1} / R^{*}\right)+\alpha_{\pi} \mathrm{E}_{t} \ln \left(\pi_{t-i} / \pi^{*}\right)+\alpha_{y} \mathrm{E}_{t} \ln \left(y_{t-i} / y^{*}\right), \quad i=-1,0,1,
$$

where $y^{*}$ denotes the nonstochastic Ramsey-steady-state level of aggregate demand and $R^{*}, \pi^{*}, \alpha_{R}, \alpha_{\pi}$, and $\alpha_{y}$ are parameters. The index $i$ can take three values 1,0 , and -1 . When $i=1$, we refer to the interest-rate rule as backward looking, when $i=0$ as contemporaneous, and when $i=-1$ as forward looking. The reason why we focus on interest-rate feedback rules belonging to this class is that they are defined in terms of readily available macroeconomic indicators.

We note that the type of monetary-policy rules that are typically analyzed in the related literature require no less information on the part of the policymaker than the feedback rule given in Eq. (6). This is because the rules most commonly studied feature an output gap measure defined as deviations of output from the level that would be obtained in the absence of nominal rigidities. Computing the flexible-price level of aggregate activity requires the policymaker to know not just the deterministic steady state of the economywhich is the information needed to implement the interest-rate rule given in Eq. (6) - but also the joint distribution of all the shocks driving the economy and the current realizations of such shocks.

We will also study an interest-feedback rule whereby the change in the nominal interest rate is set as a function of its own lag, lagged output growth, and lagged deviations of inflation from target. Formally, this monetary rule is given by

$$
\ln \left(R_{t} / R_{t-1}\right)=\alpha_{R} \ln \left(R_{t-1} / R_{t-2}\right)+\alpha_{\pi} \ln \left(\pi_{t-1} / \pi^{*}\right)+\alpha_{y} \ln \left(y_{t-1} / y_{t-2}\right) .
$$

This specification of monetary policy is of interest because its implementation requires minimal information. Specifically, the central bank need not know the steady-state values of output or the nominal interest rate. Furthermore, implementation of this rule does not require knowledge of current or future expected values of inflation or output.

\subsection{Firms}

Each variety $i \in[0,1]$ is produced by a single firm in a monopolistically competitive environment. Each firm $i$ produces output using as factor inputs capital services, $k_{i t}$, and labor services, $h_{i t}$. The production technology is given by $z_{t} F\left(k_{i t}, h_{i t}\right)-\chi$, where the function $F$ is assumed to be homogenous of degree one, concave, and strictly increasing in both arguments. The variable $z_{t}$ denotes an exogenous, aggregate productivity shock. The 
parameter $\chi$ introduces fixed costs of production, which are meant to soak up steady-state profits in conformity with the stylized fact that profits are close to zero on average in the U.S. economy.

It follows from our analysis of private and public absorption behavior that the aggregate demand for good $i$, denoted by $a_{i t} \equiv c_{i t}+i_{i t}+g_{i t}$, is given by $a_{i t}=\left(P_{i t} / P_{t}\right)^{-\eta} a_{t}$, where $a_{t} \equiv c_{t}+i_{t}+g_{t}$ denotes aggregate absorption.

We introduce a demand for money by firms by assuming that wage payments are subject to a cash-in-advance constraint of the form

$$
m_{i t}^{\mathrm{f}} \geqslant v^{\mathrm{f}} w_{t} h_{i t},
$$

where $m_{i t}^{\mathrm{f}} \equiv M_{i t}^{\mathrm{f}} / P_{t}$ denotes the demand for real money balances by firm $i$ in period $t, M_{i t}^{\mathrm{f}}$ denotes nominal money holdings of firm $i$ in period $t$, and $v^{\mathrm{f}} \geqslant 0$ is a parameter denoting the fraction of the wage bill that must be backed with monetary assets. We assume that the firm must satisfy demand at the posted price. Formally, we impose

$$
z_{t} F\left(k_{i t}, h_{i t}\right)-\chi \geqslant\left(\frac{P_{i t}}{P_{t}}\right)^{-\eta} a_{t} .
$$

Prices are assumed to be sticky à la Calvo (1983) and Yun (1996). Specifically, each period fraction $\alpha \in[0,1)$ of randomly picked firms is not allowed to change the nominal price of the good it produces. We assume no indexation of prices. This assumption is in line with the empirical evidence presented in Cogley and Sbordone (2004) and Levin et al. (2005). The remaining $(1-\alpha)$ firms choose prices optimally.

\section{Computation, calibration, and welfare measure}

We wish to find the monetary- and fiscal-policy-rule combination (i.e., a value for $\alpha_{\pi}, \alpha_{y}$, $\alpha_{R}$, and $\gamma_{1}$ ) that is optimal and implementable within the simple family defined by Eqs. (5) and (6). For a policy to be implementable, we impose three requirements: first, the rule must ensure local uniqueness of the rational expectations equilibrium. Second, the rule must induce nonnegative equilibrium dynamics for the nominal interest rate. Because we approximate the solution to the equilibrium using perturbation methods, and because this method is ill suited to handle nonnegativity constraints, we approximate the zero bound constraint by requiring a low volatility of the nominal interest rate relative to its target value. Specifically, we impose the condition $2 \sigma_{R}<R^{*}$, where $\sigma_{R}$ denotes the unconditional standard deviation of the nominal interest rate. Third, we limit attention to policy coefficients in the interval $[0,3]$. The size of this interval is arbitrary, but we feel that policy coefficients larger than 3 or negative would be difficult to communicate to policymakers or the public. Most of our results, however, are robust to expanding the size of the interval.

For an implementable policy to be optimal, the contingent plans for consumption and hours of work associated with that policy must yield the highest level of unconditional lifetime utility. Formally, we look for policy parameters that maximize $\mathrm{E}\left[V_{t}\right]$, where

$$
V_{t} \equiv \mathrm{E}_{t} \sum_{j=0}^{\infty} \beta^{j} \mathrm{U}\left(c_{t+j}, h_{t+j}\right)
$$

and $\mathrm{E}$ denotes the unconditional expectations operator. Our results are robust to following the alternative strategy of selecting policy parameters to maximize $V_{t}$ itself, conditional 
upon the initial state of the economy being the nonstochastic steady state (see SchmittGrohé and Uribe, 2004c). As a point of reference for policy evaluation we use the timeinvariant stochastic Ramsey-optimal allocation. We report conditional and unconditional welfare costs of following the optimized simple policy rule relative to the Ramsey policy. We compute second-order accurate solutions to policy functions using the methodology and computer code of Schmitt-Grohé and Uribe (2004a). Matlab code used to generate the results shown in the subsequent sections are available on the authors' websites.

\subsection{Calibration and functional forms}

We assume that the period utility function is given by $\mathrm{U}(c, h)=\left\{\left[c(1-h)^{\gamma}\right]^{1-\sigma}-1\right\} /$ $(1-\sigma)$. The production function, excluding fixed costs, is of the Cobb-Douglas form, $F(k, h)=k^{\theta} h^{1-\theta}$. To obtain the deep structural parameters, we calibrate the model to the U.S. economy, choosing the time unit to be one quarter. Table 1 presents the deep structural parameter values implied by our calibration. The details of the calibration strategy are contained in the expanded version of this paper (Schmitt-Grohé and Uribe, 2006b).

The driving forces $g_{t}$ and $z_{t}$ are parameterized as in Schmitt-Grohé and Uribe (2006a). Government purchases are assumed to follow a univariate autoregressive process of the form

$$
\ln \left(g_{t} / \bar{g}\right)=\rho_{\mathrm{g}} \ln \left(g_{t-1} / \bar{g}\right)+\varepsilon_{t}^{\mathrm{g}},
$$

where $\bar{g}$ is a constant. The first-order autocorrelation, $\rho_{\mathrm{g}}$, is set to 0.87 and the standard deviation of $\varepsilon_{t}^{\mathrm{g}}$ to 0.016 . Productivity shocks are also assumed to follow a univariate autoregressive process

$$
\ln z_{t}=\rho_{z} \ln z_{t-1}+\varepsilon_{t}^{z}
$$

where $\rho_{z}=0.856$ and the standard deviation of $\varepsilon_{t}^{z}$ is 0.0064 .

Table 1

Deep structural parameters

\begin{tabular}{lll}
\hline Parameter & Value & Description \\
\hline$\sigma$ & 2 & Preference parameter, $\mathrm{U}(c, h)=\left\{\left[c(1-h)^{\gamma}\right]^{1-\sigma}-1\right\} /(1-\sigma)$ \\
$\theta$ & 0.3 & Cost share of capital, $F(k, h)=k^{\theta} h^{1-\theta}$ \\
$\beta$ & $1.04^{-1 / 4}$ & Quarterly subjective discount rate \\
$\eta$ & 5 & Price elasticity of demand \\
$\bar{g}$ & 0.0552 & Steady-state level of government purchases \\
$\delta$ & $1.1^{(1 / 4)}-1$ & Quarterly depreciation rate \\
$v^{\mathrm{f}}$ & 0.6307 & Fraction of wage payments held in money \\
$v^{\mathrm{h}}$ & 0.3496 & Fraction of consumption held in money \\
$\alpha$ & 0.8 & Share of firms that can change their price each period \\
$\gamma$ & 3.6133 & Preference parameter \\
$\psi$ & 0 & Investment adjustment cost parameter \\
$\chi$ & 0.0968 & Fixed cost parameter \\
$\rho_{\mathrm{g}}$ & 0.87 & Serial correlation of government spending \\
$\sigma^{\varepsilon^{\mathrm{g}}}$ & 0.016 & Standard deviation of innovation to government purchases \\
$\rho_{z}$ & 0.8556 & Serial correlation of productivity shock \\
$\sigma^{\varepsilon^{z}}$ & 0.0064 & Standard deviation of innovation to productivity shock \\
\hline
\end{tabular}




\subsection{Measuring welfare costs}

We conduct policy evaluations by computing the welfare cost of a particular monetary and fiscal regime relative to the time-invariant stochastic equilibrium allocation associated with the Ramsey policy. Consider the Ramsey policy, denoted by $r$, and an alternative policy regime, denoted by $a$. We define the welfare associated with the time-invariant stochastic allocation implied by the Ramsey policy conditional on a particular state of the economy in period 0 as

$$
V_{0}^{r}=\mathrm{E}_{0} \sum_{t=0}^{\infty} \beta^{t} \mathrm{U}\left(c_{t}^{r}, h_{t}^{r}\right),
$$

where $c_{t}^{r}$ and $h_{t}^{r}$ denote the contingent plans for consumption and hours under the Ramsey policy. Similarly, define the conditional welfare associated with policy regime $a$ as

$$
V_{0}^{a}=\mathrm{E}_{0} \sum_{t=0}^{\infty} \beta^{t} \mathrm{U}\left(c_{t}^{a}, h_{t}^{a}\right) .
$$

We assume that at time zero all state variables of the economy equal their respective Ramsey-steady-state values. Because the nonstochastic steady state is the same across all policy regimes we consider, computing expected welfare conditional on the initial state being the nonstochastic steady state ensures that the economy begins from the same initial point under all possible policies. ${ }^{5}$

Let $\lambda^{\mathrm{c}}$ denote the welfare cost of adopting policy regime $a$ instead of the Ramsey policy conditional on a particular state in period zero. We define $\lambda^{\mathrm{c}}$ as the fraction of regime $r$ 's consumption process that a household would be willing to give up to be as well off under regime $a$ as under regime $r$. Formally, $\lambda^{\mathrm{c}}$ is implicitly defined by

$$
V_{0}^{a}=\mathrm{E}_{0} \sum_{t=0}^{\infty} \beta^{t} \mathrm{U}\left(\left(1-\lambda^{\mathrm{c}}\right) c_{t}^{r}, h_{t}^{r}\right) .
$$

Similarly, let $\lambda^{\mathrm{u}}$ denote the unconditional welfare cost of following policy regime $a$ instead of the Ramsey policy. Formally,

$$
\mathrm{E} V_{0}^{a}=\mathrm{E} \sum_{t=0}^{\infty} \beta^{t} \mathrm{U}\left(\left(1-\lambda^{\mathrm{u}}\right) c_{t}^{r}, h_{t}^{r}\right)
$$

We approximate $\lambda^{\mathrm{c}}$ and $\lambda^{\mathrm{u}}$ up to second order of accuracy. For details see the expanded version of this paper (Schmitt-Grohé and Uribe, 2006b).

\section{A cashless economy}

Consider a nonmonetary economy. Specifically, eliminate the cash-in-advance constraints on households and firms by setting $v^{\mathrm{h}}=v^{\mathrm{f}}=0$ in Eqs. (2) and (8). The fiscal

\footnotetext{
${ }^{5}$ It is of interest to investigate the robustness of our results with respect to alternative initial conditions. For, in principle, the welfare ranking of the alternative policies will depend upon the assumed value for (or distribution of) the initial state vector. In an earlier version of this paper (Schmitt-Grohé and Uribe, 2004c), we conduct policy evaluations conditional on an initial state different from the Ramsey steady state and obtain similar results to those presented in this paper.
} 
authority is assumed to have access to lump-sum taxes and to follow a passive fiscal policy. That is, the fiscal-policy rule is given by Eqs. (4) and (5) with $\gamma_{1} \in\left(0,2 / \pi^{*}\right)$ and $\tau_{t}^{\mathrm{D}}=0$. This economy is of interest for it most resembles the canonical neo-Keynesian model studied in the related literature on optimal policy (see Clarida et al., 1999, and the references cited therein). This body of work studies optimal monetary policy in the context of a cashless economy with nominal rigidities and no fiscal authority. For analytical purposes, the absence of a fiscal authority is equivalent to modeling a government that operates under passive fiscal policy and collects all of its revenue via lump-sum taxation. We wish to highlight, however, two important differences between the economy studied here and the one typically considered in the related literature. Namely, in our economy there is capital accumulation and no subsidy to factor inputs aimed at offsetting the distortions arising from monopolistic competition.

Panel A of Table 2 reports policy evaluations for the cashless economy. The point of comparison for our policy evaluation is the time-invariant stochastic real allocation associated with the Ramsey policy. The table reports conditional and unconditional welfare costs, $\lambda^{\mathrm{c}}$ and $\lambda^{\mathrm{u}}$, as defined in Eqs. (9) and (10). Under the Ramsey policy inflation is virtually equal to zero at all times. ${ }^{6}$ One may wonder why in an economy featuring sticky prices as the single nominal friction, the volatility of inflation is not exactly equal to zero at all times under the Ramsey policy. The reason is that we do not follow the standard practice of subsidizing factor inputs to eliminate the distortion introduced by monopolistic competition in product markets. Introducing such a subsidy would result in a constant Ramsey-optimal rate of inflation equal to zero. ${ }^{7}$

We consider seven different monetary policies: four constrained-optimal interest-rate feedback rules and three nonoptimized rules. In the constrained-optimal rule labeled no smoothing, we search over the policy coefficients $\alpha_{\pi}$ and $\alpha_{y}$ keeping $\alpha_{R}$ fixed at zero. The second constrained-optimal rule, labeled smoothing in the table, allows for interest-rate inertia by setting optimally all three coefficients, $\alpha_{\pi}, \alpha_{y}$, and $\alpha_{R}$.

We find that the best no-smoothing interest-rate rule calls for an aggressive response to inflation and a mute response to output. The inflation coefficient of the optimized rule takes the largest value allowed in our search, namely $3 .^{8}$ The optimized rule is quite effective as it delivers welfare levels remarkably close to those achieved under the Ramsey policy. At the same time, the rule induces a stable rate of inflation, a feature that also characterizes the Ramsey policy.

We next study a case in which the central bank can smooth interest rates over time. Our numerical search yields that the optimal policy coefficients are $\alpha_{\pi}=3, \alpha_{y}=0.01$, and $\alpha_{R}=0.84$. The fact that the optimized rule features substantial interest-rate inertia means that the monetary authority reacts to inflation much more aggressively in the long run than in the short run. The fact that the interest rule is not superinertial (i.e., $\alpha_{R}$ does not exceed

\footnotetext{
${ }^{6}$ In the deterministic steady state of the Ramsey economy, the inflation rate is zero.

${ }^{7}$ Formally, one can show that setting $\tau_{t}^{\mathrm{D}}=1 /(1-\eta)$ and $\pi_{t}=1$ for all $t \geqslant 0$ and eliminating the depreciation allowance the equilibrium conditions collapse to those associated with the flexible-price, perfect-competition version of the model. Because the real allocation implied by the latter model is Pareto efficient, it follows that setting $\pi_{t}=1$ at all times must be Ramsey-optimal in the economy with sticky prices and factor subsidies.

${ }^{8}$ Removing the upper bound on policy parameters optimal policy calls for a much larger inflation coefficient, a zero output coefficient, and yields a negligible improvement in welfare. The unconstrained policy-rule coefficients are $\alpha_{\pi}=332$ and $\alpha_{y}=0$. The associated welfare gain is about one-thousandth of one percent of consumption conditionally and unconditionally.
} 
Table 2

Optimal monetary policy

\begin{tabular}{|c|c|c|c|c|c|c|c|}
\hline & $\alpha_{\pi}$ & $\alpha_{y}$ & $\alpha_{R}$ & $\begin{array}{l}\text { Conditional welfare } \\
\operatorname{cost}\left(\lambda^{\mathrm{c}} \times 100\right)\end{array}$ & $\begin{array}{l}\text { Unconditional welfare } \\
\operatorname{cost}\left(\lambda^{\mathrm{u}} \times 100\right)\end{array}$ & $\sigma_{\pi}$ & $\sigma_{R}$ \\
\hline \multicolumn{8}{|c|}{ A. The cashless economy } \\
\hline & \multicolumn{7}{|c|}{ Optimized rules } \\
\hline \multicolumn{8}{|c|}{ Contemporaneous $(i=0)$} \\
\hline Smoothing & 3 & 0.01 & 0.84 & 0.000 & 0.000 & 0.04 & 0.29 \\
\hline No smoothing & 3 & 0.00 & - & 0.000 & 0.001 & 0.14 & 0.42 \\
\hline Backward $(i=1)$ & 3 & 0.03 & 1.71 & 0.001 & 0.001 & 0.10 & 0.23 \\
\hline Forward $(i=-1)$ & 3 & 0.07 & 1.58 & 0.002 & 0.003 & 0.19 & 0.27 \\
\hline \multicolumn{8}{|l|}{ Nonoptimized rules } \\
\hline Taylor rule $(i=0)$ & 1.5 & 0.5 & - & 0.451 & 0.522 & 3.19 & 3.08 \\
\hline Simple Taylor rule & 1.5 & - & - & 0.014 & 0.019 & 0.58 & 0.87 \\
\hline Inflation targeting & - & - & - & -0.000 & 0.000 & 0 & 0.27 \\
\hline \multicolumn{8}{|c|}{ B. The monetary economy } \\
\hline $\begin{array}{l}\text { Ramsey policy } \\
\text { Optimized rules }\end{array}$ & - & - & - & 0 & 0 & 0.01 & 0.27 \\
\hline \multicolumn{8}{|c|}{ Contemporaneous $(i=0)$} \\
\hline Smoothing & 3 & 0.01 & 0.80 & 0.000 & 0.000 & 0.04 & 0.29 \\
\hline No smoothing & 3 & 0.00 & - & 0.001 & 0.001 & 0.14 & 0.41 \\
\hline \multicolumn{8}{|l|}{ Nonoptimized rules } \\
\hline Taylor rule $(i=0)$ & 1.5 & 0.5 & - & 0.598 & 0.709 & 3.93 & 3.76 \\
\hline Simple Taylor rule & 1.5 & - & - & 0.011 & 0.015 & 0.56 & 0.85 \\
\hline Inflation targeting & - & - & - & -0.000 & 0.000 & 0 & 0.27 \\
\hline
\end{tabular}

Notes: (1) The interest-rate rule is given by $\ln \left(R_{t} / R^{*}\right)=\alpha_{R} \ln \left(R_{t-1} / R^{*}\right)+\alpha_{\pi} \mathrm{E}_{t} \ln \left(\pi_{t-i} / \pi^{*}\right)+\alpha_{y} \mathrm{E}_{t} \ln \left(y_{t-i} / y^{*}\right)$, $i=-1,0,1$. (2) In the optimized rules, the policy parameters $\alpha_{\pi}, \alpha_{y}$, and $\alpha_{R}$ are restricted to lie in the interval [0,3]. (3) Conditional and unconditional welfare costs, $\lambda^{\mathrm{c}} \times 100$ and $\lambda^{\mathrm{u}} \times 100$, are defined as the percentage decrease in the Ramsey-optimal consumption process necessary to make the level of welfare under the Ramsey policy identical to that under the evaluated policy. Thus, a positive figure indicates that welfare is higher under the Ramsey policy than under the alternative policy. (4) The standard deviation of inflation and the nominal interest rate is measured in percent per year.

unity) means that the monetary authority is backward looking. So, again, as in the case without smoothing optimal policy calls for a large response to inflation deviations in order to stabilize the inflation rate and for no response to deviations of output from the steady state. The welfare gain of allowing for interest-rate smoothing is insignificant. Taking the difference between the welfare costs associated with the optimized rules with and without interest-rate smoothing reveals that agents would be willing to give up less than $0.001 \%$, that is, less than one one-thousandth of one percent, of their consumption stream under the optimized rule with smoothing to be as well off as under the optimized policy without smoothing.

The finding that allowing for optimal smoothing yields only negligible welfare gains spurs us to investigate whether rules featuring suboptimal degrees of inertia or responsiveness to inflation can produce nonnegligible welfare losses at all. Panel (a) of Fig. 1 shows that provided the central bank does not respond to output, $\alpha_{y}=0$, varying $\alpha_{\pi}$ and $\alpha_{R}$ between 0 and 3 typically leads to economically negligible welfare losses of less than five one-hundredth of one percent of consumption. The graph shows with crosses 

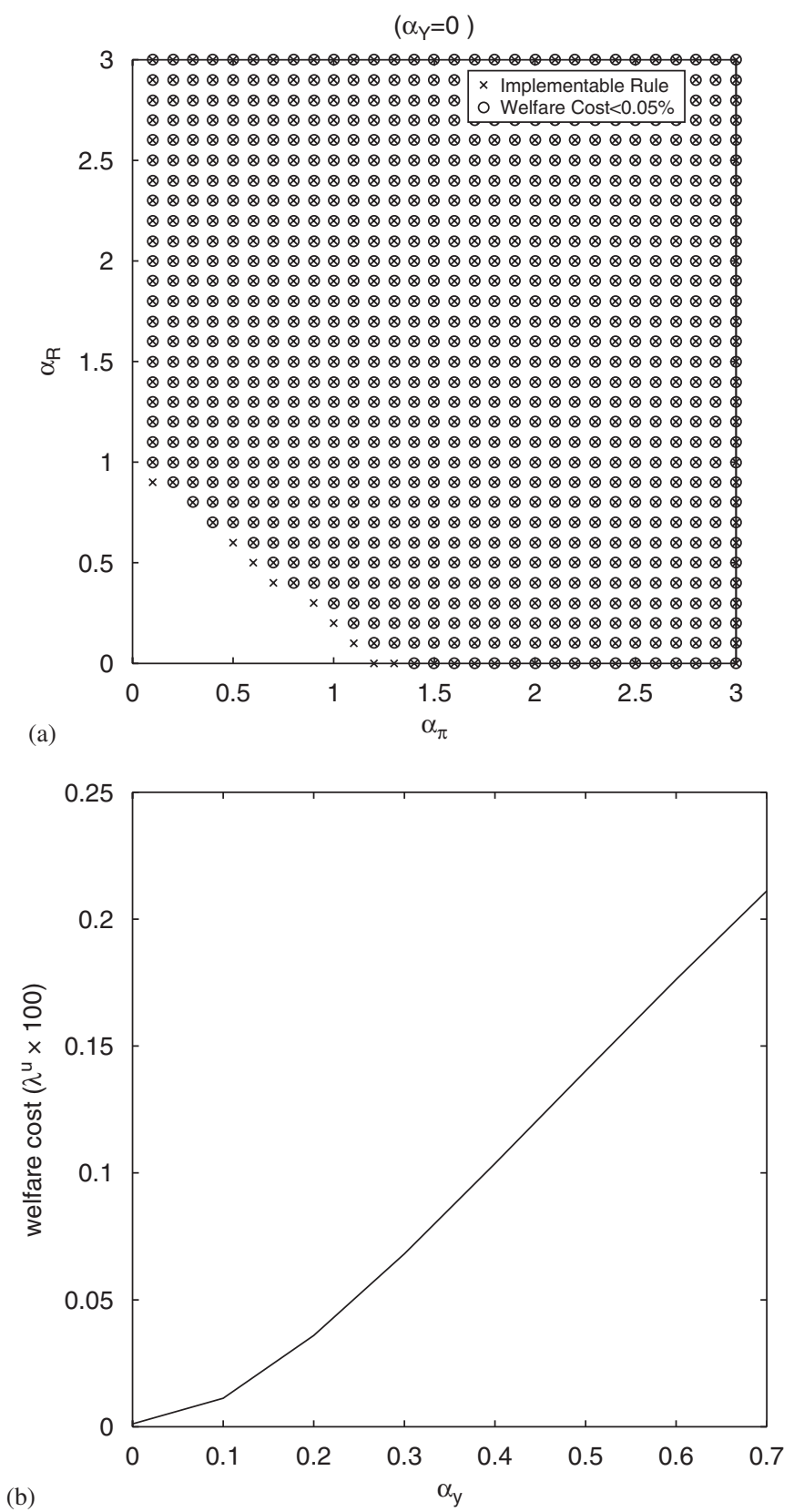

Fig. 1. The cashless economy: (a) implementability and welfare and (b) the importance of not responding to output.

combinations of $\alpha_{\pi}$ and $\alpha_{R}$ that are implementable and with circles combinations that are implementable and that yield welfare costs less than $0.05 \%$ of consumption relative to the Ramsey policy. 
The blank area in the figure identifies $\alpha_{\pi}$ and $\alpha_{R}$ combinations that are not implementable either because the equilibrium fails to be locally unique or because the implied volatility of interest rates is too high. This is the case for values of $\alpha_{\pi}$ and $\alpha_{R}$ such that the policy stance is passive in the long run, that is $\alpha_{\pi} /\left(1-\alpha_{R}\right)<1$. For these parameter combinations the equilibrium is not locally unique. This finding is a generalization of the result, that when the inflation coefficient is less than unity $\left(\alpha_{\pi}<1\right)$ the equilibrium is indeterminate, which is obtained in the absence of interest-rate smoothing $\left(\alpha_{R}=0\right)$. We also note that the result that passive interest-rate rules (together with passive fiscal policy) renders the equilibrium indeterminate is typically derived in the context of models that abstract from capital accumulation. It is therefore reassuring that this particular abstraction appears to be of no consequence for the finding that (long-run) passive policy is inconsistent with local uniqueness of the rational expectations equilibrium. Similarly, we find that determinacy is obtained for policies that are active in the long run, $\alpha_{\pi} /\left(1-\alpha_{R}\right)>1$.

More importantly, panel (a) of Fig. 1 shows that virtually all parameterizations of the interest-rate feedback rule that are implementable yield about the same level of welfare as the Ramsey equilibrium. This finding suggests a simple policy prescription, namely, that any policy parameter combination that is irresponsive to output and active in the long run is equally desirable from a welfare point of view.

One possible reaction to the finding that implementability-preserving variations in $\alpha_{\pi}$ and $\alpha_{R}$ have little welfare consequences may be that in the class of models we consider welfare is flat in a large neighborhood around the optimum parameter configuration, so that it does not really matter what the government does. This turns out not to be the case in the economy studied here. Recall that in the welfare calculations underlying panel (a) of Fig. 1 the response coefficient on output, $\alpha_{y}$, was kept constant and equal to zero. Indeed, as we show in the next subsection, interest-rate rules that lean against the wind by raising the nominal interest rate when output is above trend can be associated with sizable welfare costs.

\subsection{The importance of not responding to output}

Panel (b) of Fig. 1 illustrates the consequences of introducing a cyclical component to the interest-rate rule. It shows that the welfare costs of varying $\alpha_{y}$ can be large, thereby underlining the importance of not responding to output. The figure shows the welfare cost of deviating from the optimal output coefficient $\left(\alpha_{y} \approx 0\right)$ while keeping the inflation coefficient of the interest-rate rule at its optimal value $\left(\alpha_{\pi}=3\right)$ and not allowing for interest-rate smoothing $\left(\alpha_{R}=0\right)$. Welfare costs are monotonically increasing in $\alpha_{y}$. When $\alpha_{y}=0.7$, the welfare cost is over two-tenths of one percent of the consumption stream associated with the Ramsey policy. This is a significant figure in the realm of policy evaluation at business-cycle frequency. ${ }^{9}$ This finding suggests that bad policy can have significant welfare costs in our model and that policy mistakes are committed when policymakers are unable to resist the temptation to respond to output fluctuations.

It follows that sound monetary policy calls for sticking to the basics of responding to inflation alone. ${ }^{10}$ This point is conveyed with remarkable simplicity by

\footnotetext{
${ }^{9} \mathrm{~A}$ similar result is obtained if one allows for interest-rate smoothing with $\alpha_{R}$ taking its optimized value of 0.84 .

${ }^{10}$ Other authors have also argued that countercyclical interest-rate policy may be undesirable (e.g., Ireland, 1997; Rotemberg and Woodford, 1997).
} 
comparing the welfare consequences of a simple interest-rate rule that responds only to inflation with a coefficient of 1.5 to those of a standard Taylor rule that responds to inflation as well as output with coefficients 1.5 and 0.5 , respectively. Panel A of Table 2 shows that the Taylor rule that responds to output is significantly welfare inferior to the simple interest-rate rule that responds solely to inflation. Specifically, the welfare cost of responding to output is about half a percentage point of consumption. ${ }^{11}$

\subsection{Inflation targeting}

The Ramsey-optimal monetary policy implies near complete inflation stabilization (see panel A of Table 2). It is reasonable to conjecture, therefore, that inflation targeting, interpreted to be any monetary policy capable of bringing about zero inflation at all times $\left(\pi_{t}=1\right.$ for all $\left.t\right)$, would induce business cycles virtually identical to those associated with the Ramsey policy. We confirm this conjecture by computing the welfare cost associated with inflation targeting. The unconditional welfare cost of targeting inflation relative to the Ramsey policy is virtually nil. Curiously, conditional on the initial state being the deterministic Ramsey steady state, inflation targeting welfare dominates the Ramsey policy albeit by an insignificant amount. This result can be understood by the fact that the Ramsey policy maximizes welfare along a time-invariant equilibrium distribution.

\subsection{Backward-and forward-looking interest-rate rules}

An important issue in monetary policy is what measures of inflation and aggregate activity the central bank should respond to. In particular, a question that has received considerable attention among academic economists and policymakers is whether the monetary authority should respond to past, current, or expected future values of output and inflation. Here, we address this question by computing optimal backward- and forward-looking interest-rate rules. That is, in Eq. (6) we let $i$ take the values -1 and +1 . Panel A of Table 2 shows that there are no welfare gains from targeting expected future values of inflation and output as opposed to current or lagged values of these macroeconomic indicators. Also a muted response to output continues to be optimal under backward- or forward-looking rules.

Under a forward-looking rule without smoothing $\left(\alpha_{R}=0\right)$, the rational expectations equilibrium is indeterminate for all values of the inflation and output coefficients in the interval [0,3]. This result is in line with that obtained by Carlstrom and Fuerst (2005). These authors consider an environment similar to ours and characterize determinacy of equilibrium for interest-rate rules that depend only on the rate of inflation. Our results extend the findings of Carlstrom and Fuerst to the case in which output enters in the feedback rule. $^{12}$

\footnotetext{
${ }^{11}$ The simple interest-rate rule that responds solely to inflation is implementable, whereas the standard Taylor rule is not, because it implies too high a volatility of nominal interest rates.

${ }^{12}$ Carlstrom and Fuerst (2005) comment that including output in the interest-rate rule would have minor effects on local determinacy conditions (see their footnote 4).
} 


\section{A monetary economy}

We next introduce money into the model by assuming that the parameters $v^{\mathrm{h}}$ and $v^{\mathrm{f}}$ governing the demands for money by households and firms take their baseline values of 0.35 and 0.63 , respectively. All other aspects of the model are as in the cashless economy analyzed in the preceding section.

In this model there exists a tradeoff between inflation stabilization, aimed at neutralizing the distortions stemming from sluggish price adjustment, and nominal-interest-rate stabilization, aimed at dampening the distortions introduced by the two monetary frictions. Movements in the opportunity cost of holding money distort both the effective wage rate, via the working-capital constraint faced by firms, and the leisure-consumption margin, via the cash-in-advance constraint faced by households. We find, however, that this tradeoff is not quantitatively important (see panel B of Table 2). The Ramsey monetary policy calls for the same degrees of inflation and nominal-interest-rate volatilities as in the cashless economy. ${ }^{13}$ Furthermore, the welfare-maximizing interest-rate rules, with and without interest-rate smoothing, are virtually identical to those obtained in the cashless economy. That is, $\alpha_{\pi}$ takes the largest value allowed in our grid, 3 , the output coefficient $\alpha_{y}$ is practically nil, and the interest-rate-smoothing parameter is significant, $\alpha_{R}=0.8$. The optimized interest-rate rule, with or without inertia, gets remarkably close to the level of welfare associated with the Ramsey allocation. The welfare costs in both cases are economically negligible. Therefore, the welfare gain of allowing for interest-rate smoothing is insignificant.

As in the cashless economy, welfare is quite insensitive to the precise magnitude of the inflation and interest-rate-smoothing coefficients provided that the output coefficient is held at zero. This point is clearly communicated by panel (a) of Fig. 2, which shows with crosses the pairs $\left(\alpha_{\pi}, \alpha_{R}\right)$ for which the equilibrium is implementable and with circles the pairs for which the equilibrium is implementable and welfare costs vis-à-vis the Ramsey equilibrium are less than $0.05 \%$ of consumption. In the figure, the output coefficient $\alpha_{y}$ is fixed at zero. Most of the implementable policy parameterizations yield welfare levels remarkably close to that implied by the Ramsey policy.

A further similarity with the cashless economy is that positive values of the output response coefficient of the interest-rate rule, $\alpha_{y}$, continue to be associated with nonnegligible welfare losses. Panel (b) of Fig. 2 plots unconditional welfare losses as a function of $\alpha_{y}$, holding the inflation coefficient at its optimal value of 3 and the laggedinterest-rate coefficient at zero. The welfare cost increases monotonically as $\alpha_{y}$ increases from 0 to 0.4 . Beyond this value, the equilibrium ceases to be implementable. ${ }^{14}$

\subsection{Difference rules}

In motivating the interest-rate rule (6), which we have been studying thus far, we argued that it demands little sophistication on the part of the policymaker, because the variables

\footnotetext{
${ }^{13}$ The Ramsey-steady-state inflation rate is $-0.55 \%$ year, slightly lower than the zero steady-state inflation rate that is optimal in the cashless economy. In the Ramsey steady state there is a tradeoff in the levels of inflation (which should be nil to avoid distortions stemming from price rigidity) and the nominal interest rate (which should be zero as called for by the Friedman rule). This tradeoff is resolved in favor of near price stability.

${ }^{14} \mathrm{~A}$ similar result was obtained if $\alpha_{R}$ were held at its optimized value of 0.8 .
} 

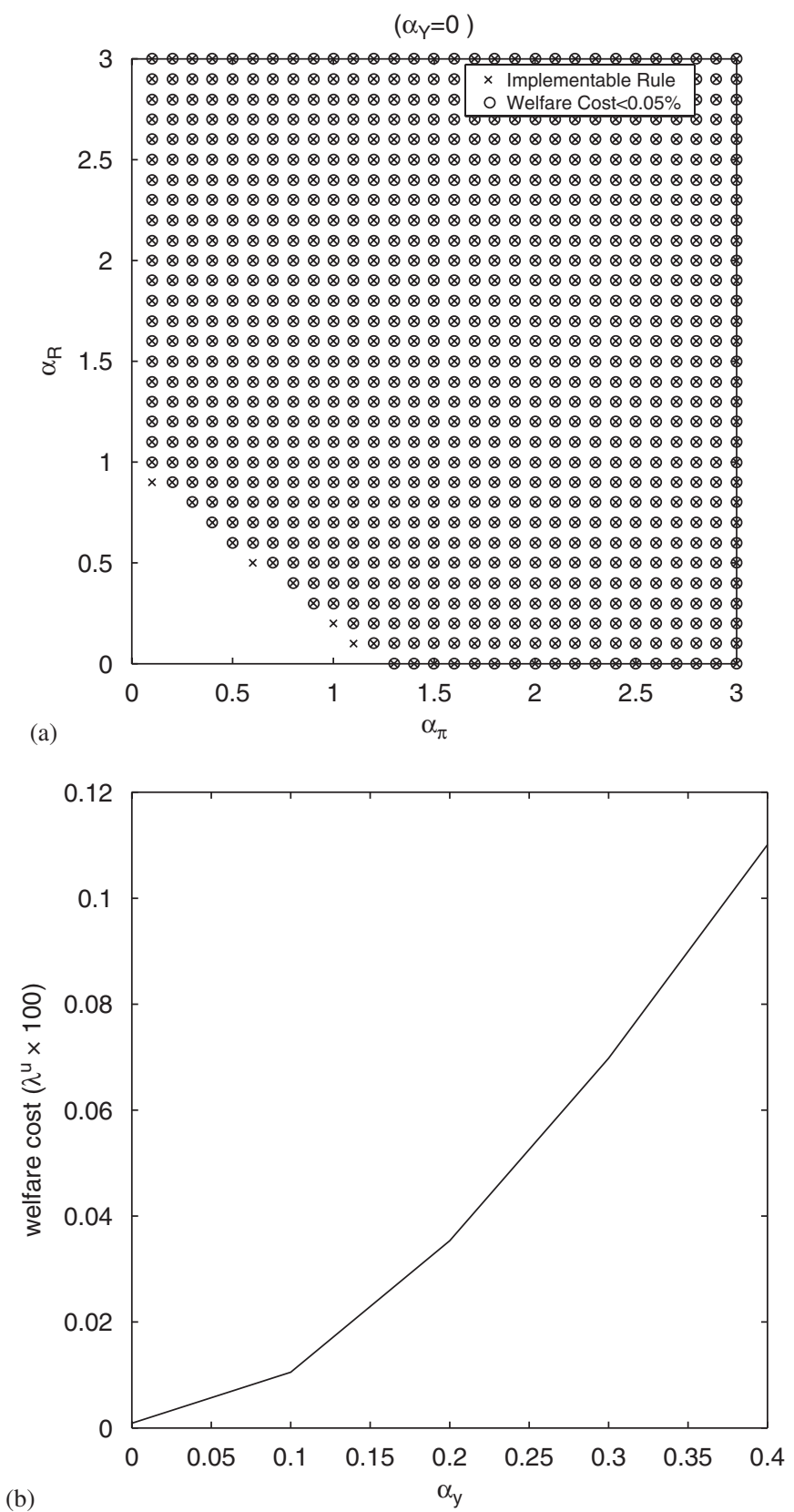

Fig. 2. The monetary economy: (a) implementability and welfare and (b) the importance of not responding to output.

involved are few and easily observable. However, one might argue that because the variables included in the rule are expressed in deviations from their nonstochastic steady state, implementation requires knowledge of the deterministic steady state. The nonstochastic steady state is, however, unobservable. Thus, the assumed rule presupposes 
a degree of knowledge that central bankers may not possess. Earlier in this section we also addressed the issue that the central banks may not have information on variables such as output and inflation on a contemporaneous basis. A way to avoid these problems is to postulate a rule that includes lagged values of time differences in prices, aggregate activity, and interest rates, as opposed to simply the contemporaneous levels of such variables. Such a rule is given in Eq. (7). Note that besides the policy coefficients $\alpha_{R}, \alpha_{\pi}$, and $\alpha_{y}$, the only parameter required for implementing this rule is the inflation target $\pi^{*}$, which is a choice for the central bank. Also, changes in prices and output appear with one-period lag. In this way, the proposed rule is simpler than the one studied thus far. Within the family of difference rules, we find that the welfare-maximizing one is given by

$$
\ln \left(R_{t} / R_{t-1}\right)=0.77 \ln \left(R_{t-1} / R_{t-2}\right)+0.75 \ln \left(\pi_{t-1} / \pi^{*}\right)+0.02 \ln \left(y_{t-1} / y_{t-2}\right) .
$$

This rule is similar in spirit to the optimal policy rule in levels. In effect, optimal policy calls for interest-rate smoothing and a mute response to output growth. The difference rule induces remarkably smooth inflation dynamics, with a standard deviation of 6 basis points at an annual rate. Furthermore, the optimal difference rule yields virtually the same level of welfare as does the optimal level rule. Eliminating the interest-rate-smoothing term by restricting $\alpha_{R}=0$ has negligible welfare consequences. Thus, as is the case under the level rule, interest-rate smoothing is unimportant from a welfare point of view.

We conclude that in the context of our model knowledge on the part of the central bank of past values of inflation and output growth provide sufficient information to implement a real allocation that is virtually identical in welfare terms to that associated with the Ramsey policy. This result is significant in light of the emphasis that the related literature places on rules that respond to unobservable measures of the output gap-typically defined as the difference between output under sticky and flexible prices.

\section{An economy with a fiscal feedback rule}

Thus far, we have restricted attention to the case of passive fiscal policy. Under passive fiscal policy, government solvency is obtained for all possible paths of the price level or other macroeconomic variables. This type of fiscal-policy regime is the one typically assumed in the related literature. But it is worthwhile asking whether from a welfare point of view a passive fiscal-policy stance is desirable. Moreover, even if it turns out that optimal policy calls for a passive fiscal regime, it is of interest to know how close one can get to the level of welfare associated with the optimized monetary and fiscal rules when fiscal policy is restricted to be active. For these reasons, in this section we study a simple fiscal-policy rule that allows for the possibility that fiscal policy be either active or passive. We first analyze an environment with lump-sum taxes and then turn attention to the case of distortionary income taxation.

\subsection{Lump-sum taxation}

Suppose that fiscal policy is defined by Eqs. (4) and (5) with $\tau_{t}^{\mathrm{D}}=0$ for all $t$. As explained earlier, when $\gamma_{1}$ takes values in the interval $\left(0,2 / \pi^{*}\right)$, fiscal policy is passive, and when $\gamma_{1}$ lies outside of this interval, fiscal policy is active. We find that the optimal monetary/fiscal rule combination without smoothing $\left(\alpha_{R}=0\right)$ features an active monetary stance and a passive fiscal stance. The optimal coefficients are $\alpha_{\pi}=3, \alpha_{y}=0.002$, and any 
$\gamma_{1} \in[0.1,1.9]$. The fact that passive fiscal policy is optimal implies that all of the results of the previous section follow. In particular, the rule delivers virtually the same level of welfare as the Ramsey-optimal policy, responding to output entails sizable welfare costs, and interest-rate smoothing adds insignificant welfare gains.

The intuition for why the optimal monetary and fiscal rule combination features passive fiscal and active monetary policy as opposed to active fiscal and passive monetary policy is the following. Recall that this is an economy in which the government has access to lumpsum taxation. Thus, any fiscal policy that ensures solvency using lump-sum taxes is nondistorting. This is the case under passive fiscal policy. If government liabilities are, say, above their target level, then lump-sum taxes are increased and with time government liabilities return to their long-run level. A rather different strategy for bringing about fiscal solvency is to use unexpected variations in the price level as a lump-sum tax/subsidy on nominal asset holdings of private households. This is what happens under active fiscal policy. For example, consider the simple case in which $\gamma_{1}=0$, so that primary fiscal deficits are exogenous, and $\alpha_{\pi}=\alpha_{y}=0$, so that monetary policy is passive (taking the form of an interest-rate peg). The only way in which fiscal solvency can be brought about in this case is through variations in the real value of government liabilities, which in turn require (unexpected) adjustments in the price level. In the economy under study movements in the price level increase the distortions stemming from the presence of nominal rigidities. This is why the strategy of reigning in government finances with surprise inflation is suboptimal.

We now address the question of how costly it is, from a welfare point of view, to follow an active fiscal stance. Fig. 3 shows with crosses the $\left(\alpha_{\pi}, \gamma_{1}\right)$ pairs that are implementable holding $\alpha_{y}$ equal to zero. The equilibrium is implementable only for combinations of active fiscal and passive monetary policy or passive fiscal and active monetary policy. It follows that policy implementability requires coordination between the fiscal authority and the central bank.

Fig. 3 also shows that most policy combinations that are implementable yield almost the same level of welfare as that associated with the Ramsey equilibrium. Specifically, the figure shows with circles the pairs $\left(\alpha_{\pi}, \gamma_{1}\right)$ implying welfare costs smaller than $0.05 \%$ of consumption vis-à-vis the Ramsey allocation. Most of the parameter specifications for which the equilibrium is implementable have a circle attached to them, indicating that agents are only marginally better off under the Ramsey-optimal rule. Notably, the figure shows that there exist active fiscal policies yielding welfare costs below five one-hundredth of one percent. This is the case, for instance, for a pure interest-rate peg, $\alpha_{\pi}=0$, and values of $\gamma_{1}$ between 2 and 3. Given our intuition for why passive fiscal policy is optimal, this result is somewhat surprising. The reason for why the welfare cost associated with active fiscal policy can be small is that this type of policy need not imply high inflation volatility. In effect, the policy combinations featuring active fiscal policy and low welfare costs shown in Fig. 3 display inflation volatilities well below one percentage point per year. We note that implementable policy combinations featuring $\gamma_{1}=0$ are not circled in Fig. 3 . This means that it is important for welfare that fiscal policy allows for some response in taxes to deviations of government liabilities from target.

\subsection{Distortionary taxation}

Consider now the more realistic case in which lump-sum taxes are unavailable and the fiscal authority must levy distortionary income taxes to finance public expenditures. 


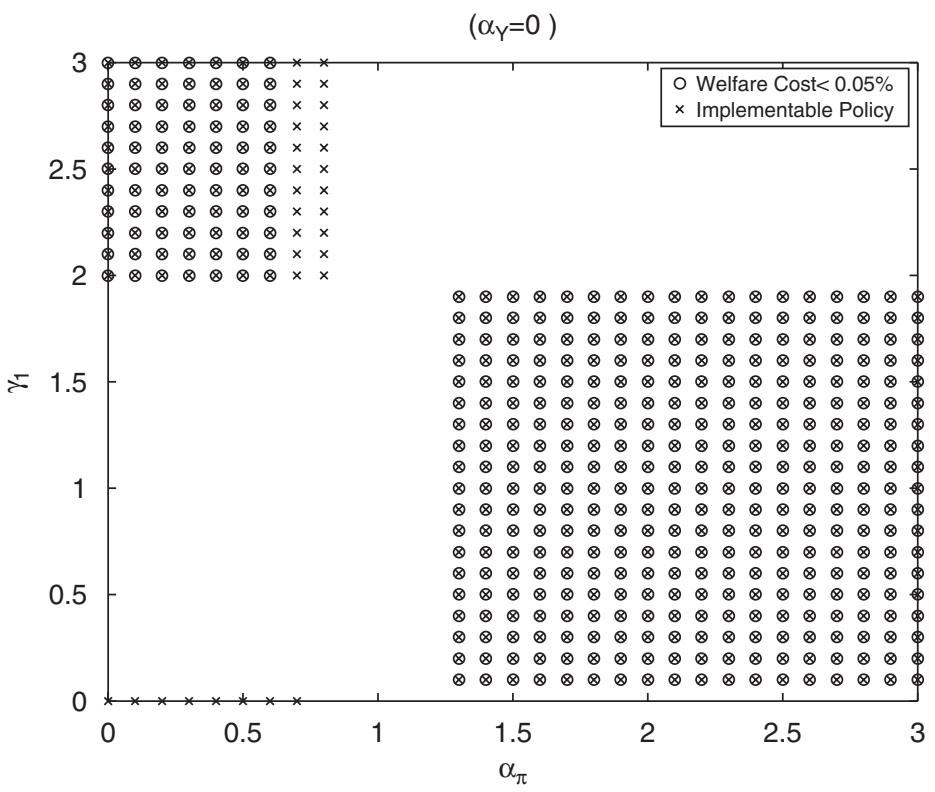

Fig. 3. Implementability regions and welfare in the model with a fiscal feedback rule and lump-sum taxation.

Specifically, total tax receipts are assumed to be given by $\tau_{t}=\tau_{t}^{\mathrm{D}} y_{t}$. We continue to use the Ramsey-optimal policy as the point of reference to perform policy evaluation. We require that in the nonstochastic steady state of the Ramsey equilibrium the debt-to-GDP ratio be $44 \%$ annually. Given this restriction, the Ramsey steady state implies an income tax rate, $\tau^{\mathrm{D}}$, equal to $15.7 \%$. As in the economy with lump-sum taxation, the tradeoff between price stability, which minimizes distortions stemming from price stickiness, and a zero nominal interest rate, which minimizes the opportunity cost of holding money, is resolved overwhelmingly in favor of price stability. In effect, the Ramsey-steady-state rate of inflation is $-0.04 \%$ /year. $^{15}$

We assume that the government commits to the fiscal and interest-rate rules given in Eqs. (5) and (6), respectively. The optimal policy-rule combination without interest-rate smoothing is given by $\ln \left(R_{t} / R^{*}\right)=3 \ln \left(\pi_{t} / \pi^{*}\right)+0.005 \ln \left(y_{t} / y^{*}\right)$ and $\tau_{t}-\tau^{*}=0.21\left(\ell_{t-1}-\right.$ $\left.\ell^{*}\right)$. The main characteristics of optimized policy in this economy are identical to those obtained in the economy with lump-sum taxes: first, the optimized interest-rate rule features an aggressive response to inflation and a muted response to output. Second, the optimized fiscal rule is passive as tax revenues increase only mildly in response to increases in government liabilities. Third, the optimized regime yields a level of welfare that is virtually identical to that implied by the Ramsey-optimal policy. The welfare cost of the optimized policy relative to the Ramsey policy conditional on the initial state being the

\footnotetext{
${ }^{15}$ Although the focus of our study is not the welfare effects of distortionary taxation, it is worth pointing out that the steady-state level of welfare under distortionary taxation is significantly below that associated with the economy in which the fiscal authority has access to lump-sum taxes. For an agent to be indifferent between living in the Ramsey steady state of the economy with distorting taxes and the one with lump-sum taxes, not taking into account the transition, he must be forced to give up more than $7 \%$ of the consumption stream that he enjoys in the lump-sum-tax world.
} 
deterministic Ramsey steady state is only $0.0029 \%$ of consumption per period. ${ }^{16}$ Finally, the optimized rule stabilizes inflation. The standard deviation of inflation is 16 basis points per year. In addition, optimal policy achieves a significant degree of tax-rate stabilization. The standard deviation of the income tax rate is 0.7 percentage points.

As in the economies with lump-sum taxes, we find that interest-rate rules featuring a large output coefficient can be disruptive from a welfare point of view. Panel (b) of Fig. 4 shows that for values of $\alpha_{y}$ between 0 and 0.5 welfare costs increase from virtually $0 \%$ to over $0.15 \%$. The latter figure is a sizable one as welfare costs at business-cycle frequency go. For values of $\alpha_{y}$ greater than 0.5 , the policy rule ceases to be implementable.

A further similarity with the economy with lump-sum taxes is that although interest-rate smoothing is optimal, its contribution to welfare is quantitatively unimportant. The optimized rule with interest-rate smoothing is given by $\alpha_{\pi}=3, \alpha_{y}=0.01, \alpha_{R}=0.88$, and $\gamma_{1}=0.26$. The conditional welfare gain relative to the optimized rule without smoothing is $0.0009 \%$ of consumption, which is economically negligible.

Unlike the economy with lump-sum taxes, the current environment with distortionary taxation speaks louder in favor of pursuing an active monetary stance together with a passive fiscal stance. Panel (a) of Fig. 4 shows with a cross the pairs $\left(\alpha_{\pi}, \gamma_{1}\right)$ that are implementable given $\alpha_{y}=0$. Essentially, all rules featuring fiscally active and monetarily passive policy or vice versa are implementable. This result is well known in the case of lump-sum taxation and flexible prices (Leeper, 1991). Here, we show that this result extends to the case of distortionary taxation and sticky prices. The figure shows with circles implementable parameter pairs $\left(\alpha_{\pi}, \gamma_{1}\right)$ for which the conditional welfare cost relative to the Ramsey policy is less than $0.05 \%$ of consumption per period. Virtually all implementable regimes featuring active monetary policy and passive fiscal policy (the southeast quarter of the plot) deliver conditional welfare levels that are insignificantly different from that implied by the Ramsey policy. By contrast, all of the implementable regimes featuring passive monetary policy and active fiscal policy have welfare costs exceeding $0.05 \%$.

\section{Conclusion}

In this paper we evaluate the stabilizing properties of simple monetary and fiscal rules. Our measure of stabilization is given by the level of welfare of private agents. By simple rules we mean ones whereby policy variables such as the nominal interest rate and taxes are set as a function of a few number of observable aggregates such as output, inflation, and government debt. We further restrict our rules to be implementable by requiring that they be associated with a unique rational expectations equilibrium and infrequent violations of the zero lower bound on nominal interest rates.

Within the class of simple and implementable rules, we find that: first, welfare is virtually insensitive to changes in the inflation coefficient in the interest-rate feedback rule. Second, interest-rate feedback rules that respond to output can be significantly harmful. Third, the optimal fiscal-policy stance is passive. Fourth, although the optimized interest-rate rule features significant interest-rate smoothing, the welfare gains associated therewith are negligible. Fifth, an interest-rate feedback rule that responds only to lagged information performs as well as one that responds to contemporaneous information. Finally, the

\footnotetext{
${ }^{16}$ We do not report unconditional welfare costs because the Ramsey dynamics feature a unit root, making it impossible to compute unconditional moments.
} 

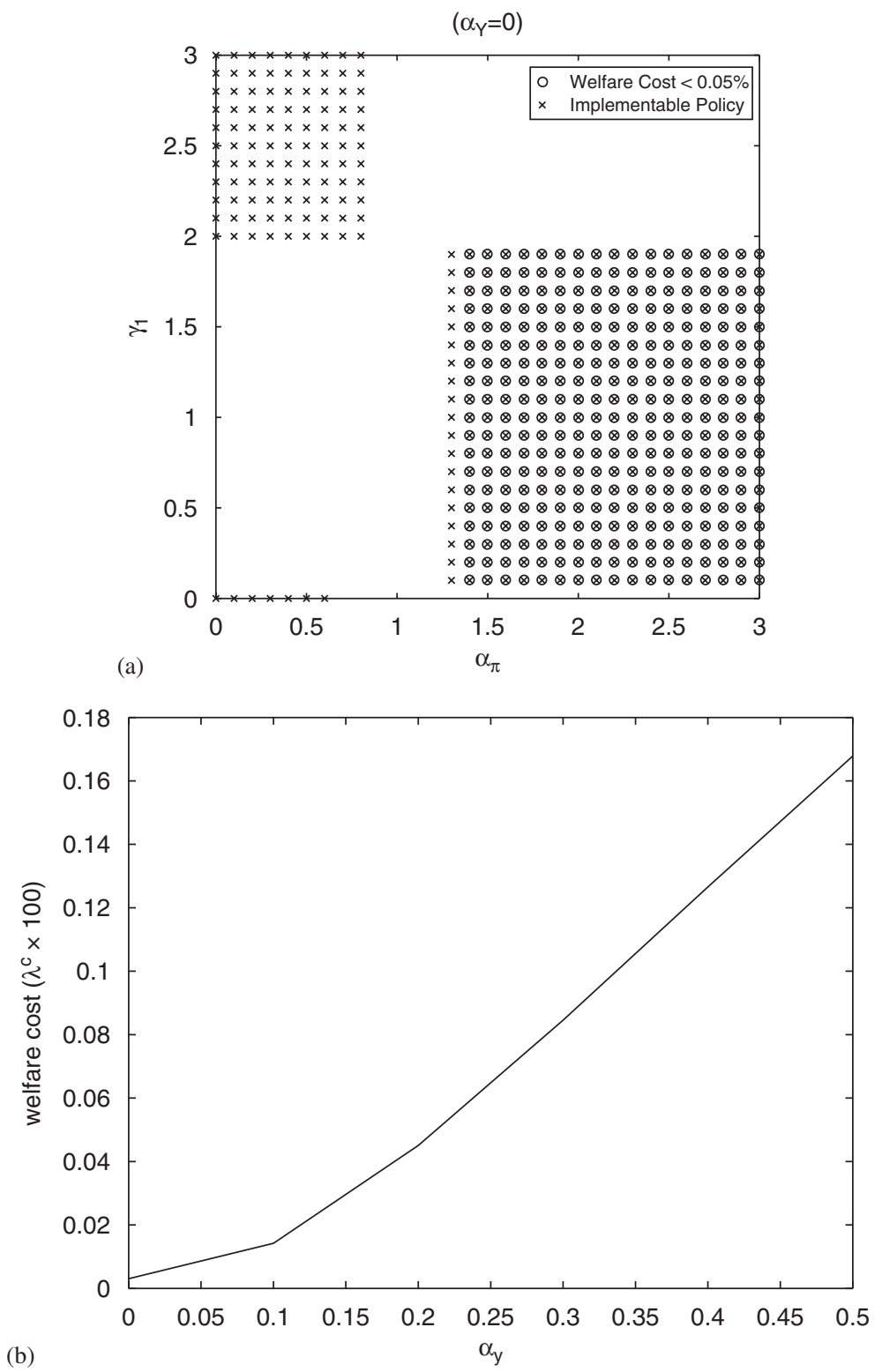

Fig. 4. The economy with distortionary taxation: (a) implementability and welfare and (b) the importance of not responding to output.

optimized simple monetary and fiscal rules attain virtually the same level of welfare as the Ramsey-optimal policy.

The model studied in this paper leaves out a number of features that have been identified as potentially important for understanding business fluctuations. Recent empirical work suggests that nominal wage stickiness, and real frictions such as habit formation, capital adjustment costs, and variable capacity utilization are important in improving the ability 
of macroeconomic models to explain U.S. business cycles. In Schmitt-Grohé and Uribe $(2005,2006 a)$, we take up the task of identifying optimal simple and implementable rules in the context of richer estimated models of the U.S. business cycle.

\section{References}

Calvo, G.A., 1983. Staggered prices in a utility-maximizing framework. Journal of Monetary Economics 12, 383-398.

Carlstrom, C.T., Fuerst, T.S., 2005. Investment and interest rate policy: a discrete time analysis. Journal of Economic Theory 123, 4-20.

Clarida, R., Galí, J., Gertler, M., 1999. The science of monetary policy: a new Keynesian perspective. Journal of Economic Literature 37, 1661-1707.

Cogley, T., Sbordone, A.M., 2004. A search for a structural Phillips curve. Manuscript, Federal Reserve Bank of New York, November.

Dupor, B., 2001. Investment and interest rate policy. Journal of Economic Theory 98, 85-113.

Favero, C.A., Monacelli, T., 2003. Monetary-fiscal mix and inflation performance: evidence from the U.S. Working Paper No. 234, Innocenzo Gasparini Institute for Economic Research (IGIER ), Bocconi University.

Galí, J., Monacelli, T., 2005. Monetary policy and exchange rate volatility in a small open economy. Review of Economic Studies 72, 707-734.

Hicks, Sir J.R., 1939. Value and Capital: an Inquiry into Some Fundamental Principles of Economic Theory. Clarendon Press, Oxford.

Ireland, P., 1997. A small, structural, quarterly model for monetary policy evaluation. Carnegie-Rochester Conference Series on Public Policy 47, 83-108.

Keynes, J.M., 1936. The General Theory of Employment, Interest, and Money. Macmillan, New York.

Khan, A., King, R.G., Wolman, A., 2003. Optimal monetary policy. Review of Economic Studies 70, 825-860.

Kollmann, R., 2003. Welfare maximizing fiscal and monetary policy rules. Mimeo, University of Bonn/March. Macroeconomic Dynamics, forthcoming.

Kydland, F.E., Prescott, E.C., 1982. Time to build and aggregate fluctuations. Econometrica 50, 1345-1370.

Leeper, E.M., 1991. Equilibria under 'Active' and 'Passive' monetary and fiscal policies. Journal of Monetary Economics 27, 129-147.

Levin, A.T., Onatski, A., Williams, J.C., Williams, N., 2005. Monetary policy under uncertainty in micro-founded macroeconometric models. Manuscript prepared for the NBER's 20th Annual Conference on Macroeconomics, March 31.

Rotemberg, J.J., Woodford, M., 1997. An optimization-based econometric framework for the evaluation of monetary policy. In: Bernanke, B.S., Rotemberg, J.J. (Eds.), NBER Macroeconomics Annual 1997. MIT Press, Cambridge, MA, London, pp. 297-346.

Rotemberg, J.J., Woodford, M., 1999. Interest rate rules in an estimated sticky price model. In: Taylor, J.B. (Ed.), Monetary Policy Rules. NBER Conference Report Series. University of Chicago Press, Chicago, London, pp. 57-119.

Schmitt-Grohé, S., Uribe, M., 2001. Stabilization policy and the costs of dollarization. Journal of Money, Credit, and Banking 33, 482-509.

Schmitt-Grohé, S., Uribe, M., 2004a. Solving dynamic general equilibrium models using a second-order approximation to the policy function. Journal of Economic Dynamics and Control 28, 755-775.

Schmitt-Grohé, S., Uribe, M., 2004b. Optimal fiscal and monetary policy under sticky prices. Journal of Economic Theory 114, 198-230.

Schmitt-Grohé, S., Uribe, M., 2004c. Optimal simple and implementable monetary and fiscal rules. NBER Working Paper No. 10253, January.

Schmitt-Grohé, S., Uribe, M., 2004d. Optimal fiscal and monetary policy under imperfect competition. Journal of Macroeconomics 26, 183-209.

Schmitt-Grohé, S., Uribe, M., 2005. Optimal inflation stabilization in a medium-scale macroeconomic model. NBER Working Paper No. 11854, November.

Schmitt-Grohé, S., Uribe, M., 2006a. Optimal fiscal and monetary policy in a medium scale macroeconomic model. In: Gertler, G., Rogoff, K. (Eds.), NBER Macroeconomics Annual 2005. MIT Press, Cambridge, MA, London, pp. 383-425. 
Schmitt-Grohé, S., Uribe, M., 2006b. Optimal simple and implementable monetary and fiscal rules: expanded version. Manuscript, Duke University, June.

Sims, C.A., 2000. Notes on the GYNSYS2 packet. Mimeo, Princeton University.

Taylor, J.B., 1993. Discretion versus policy rules in practice. Carnegie-Rochester Conference Series on Public Policy 39, 195-214.

Yun, T., 1996. Nominal price rigidity, money supply endogeneity, and business cycles. Journal of Monetary Economics 37, 345-370. 